\title{
Danish National Lymphoma Registry
}

This article was published in the following Dove Press journal:

Clinical Epidemiology

25 October 2016

Number of times this article has been viewed

\author{
Bente Arboe' \\ Pär Josefsson ${ }^{2}$ \\ Judit Jørgensen ${ }^{3}$ \\ Jacob Haaber ${ }^{4}$ \\ Paw Jensen ${ }^{5}$ \\ Christian Poulsen ${ }^{6}$ \\ Dorthe Rønnov-Jessen ${ }^{7}$ \\ Robert S Pedersen ${ }^{8}$ \\ Per Pedersen ${ }^{9}$ \\ Mikael Frederiksen ${ }^{10}$ \\ Michael Pedersen' \\ Peter de Nully Brown' \\ 'Department of Hematology, \\ Copenhagen University Hospital, \\ Rigshospitalet, ${ }^{2}$ Department \\ of Hematology, Copenhagen \\ University Hospital, Herlev Hospital, \\ Copenhagen, ${ }^{3}$ Department of \\ Hematology, Aarhus University \\ Hospital, Aarhus, ${ }^{4}$ Department of \\ Hematology, Odense University \\ Hospital, Odense, ${ }^{5}$ Department of \\ Hematology, Aalborg University \\ Hospital, Aalborg, ${ }^{6}$ Department \\ of Hematology, Roskilde Hospital, \\ Roskilde, ${ }^{7}$ Department of Hematology, \\ Vejle Hospital, Vejle, ${ }^{8}$ Department \\ of Hematology, Holstebro \\ Hospital, Holstebro, ${ }^{9}$ Department \\ of Hematology, Esbjerg Hospital, \\ Esbjerg, ${ }^{10}$ Department of Hematology, \\ Haderslev Hospital, Haderslev, \\ Denmark
}

Correspondence: Bente Arboe Department of Hematology, Copenhagen University Hospital, Rigshospitalet, Blegdamsvej 9, 2100 Copenhagen, Denmark

Tel +45 35455547

Fax +4535455362

Email bentearboe@hotmail.com
Aim of database: The Danish National Lymphoma Registry (LYFO) was established in order to monitor and improve the diagnostic evaluation and the quality of treatment of all lymphoma patients in Denmark.

Study population: The LYFO database was established in 1982 as a seminational database including all lymphoma patients referred to the departments of hematology. The database became nationwide on January 1, 2000.

Main variables: The main variables include both clinical and paraclinical variables as well as details of treatment and treatment evaluation. Up to four forms are completed for each patient: a primary registration form, a treatment form, a relapse form, and a follow-up form. Variables are used to calculate six result quality indicators (mortality 30 and 180 days after diagnosis, response to first-line treatment, and survival estimates 1,3 , and 5 years after the time of diagnosis), and three process quality indicators (time from diagnosis until the start of treatment, the presence of relevant diagnostic markers, and inclusion rate in clinical protocols).

Descriptive data: Approximately 23,000 patients were registered in the period 1982-2014 with a median age of 65 years (range: $16-100$ years) and a male/female ratio of 1.23:1. Patients can be registered with any of 42 different subtypes according to the World Health Organization classifications.

Conclusion: LYFO is a nationwide database for all lymphoma patients in Denmark and includes detailed information. This information is used for both epidemiological research and clinical follow-up as well as for administrative purposes.

Keywords: lymphoma, treatment, clinical database, quality assurance

\section{Aim of database}

Malignant lymphoma is a heterogeneous group of diseases with a wide spectrum of histological subtypes. Traditionally, malignant lymphomas have been divided into Hodgkin lymphomas and non-Hodgkin lymphomas. More than 40 subgroups are defined; both indolent and aggressive variants exist, and a wide range of treatment is used. The Danish National Lymphoma Registry (LYFO) was established in 1982, covering the western part of Denmark (Jutland and Funen), including patients with non-Hodgkin lymphoma. In 1998, Hodgkin lymphoma was also included, as the former term "Hodgkin Disease" was changed. As of January 1, 2000, the LYFO became nationwide.

The LYFO aims to register the clinical and paraclinical characteristics of patients diagnosed with malignant lymphoma in Denmark. The LYFO aims to monitor the clinical course of the disease as well as to monitor and improve the quality of treatment submit your manuscript | www.dovepress.com

Dovepress

http://dx.doi.org/10.2147/CLEP.S99470
Clinical Epidemiology 2016:8 577-58I (Thematic series on clinical quality databases in Denmark) $\mathbf{5 7 7}$ (c) (i) (5) $\odot 2016$ Arboe et al. This work is published and licensed by Dove Medical Press Limited. The full terms of this license are available at https://www.dovepress.com/terms. cC) you hereby accept the Terms. Non-commercial uses of the work are permitted without any further permission from Dove Medical Press Limited, provided the work is properly attributed. For permission for commercial use of this work, please see paragraphs 4.2 and 5 of our Terms (https://www.dovepress.com/terms.php). 
nationwide by benchmarking departments and patient risk groups.

\section{Study population}

The LYFO includes all patients diagnosed with malignant lymphoma in Denmark, referred to one of the ten departments of hematology. Patients with cutaneous lymphomas, some HIV+associated lymphomas, and some lymphomas where treatment is futile are not referred to hematological departments and hence not registered in the LYFO. This represents $\sim 5 \%$ of the lymphoma patients in Denmark. Patients diagnosed and treated outside of Denmark are not registered; according to the database registration, it is two patients per year. Patients who relapse where the initial lymphoma diagnosis was prior to start of the registry in that region are not registered. By the end of 2014, 23,000 patients were registered since 1982.

\section{Main variables}

Since it is a national quality database, all departments of hematology are obligated to register patients in the LYFO at the time of diagnosis, at the end of first-line treatment, at relapse, and at the end of follow-up or death.

Standardized forms are used to collect data on lymphoma patients (Table 1). Since 2005, the registration is submitted electronically through a secure Internet-based database system, and all information is saved electronically. For each patient, four forms are available in a consecutive manner (Figure 1).

\section{Primary registration form}

At the time of diagnosis, a primary registration form is requested. The department responsible for the treatment initiation and evaluation has the obligation to enter the form. The diagnosis is coded according to the WHO Classification of Tumours of Haematopoietic and Lymphoid Tissues. ${ }^{1}$ Since a minor subset has a discordant diagnose, this is also registered. Ann Arbor stage, B-symptoms, largest tumor diameter, Eastern Cooperative Oncology Group performance status, concomitant neoplastic diseases, and treatment strategy are required in the form. In addition to a number of laboratory test results (Table 1), information of each nodal and extranodal involvement sites is required.

\section{Treatment form}

The treatment form consists of detailed information on the first-line treatment: chemotherapy regimens, treatment with monoclonal antibodies, radiotherapy, radioimmunotherapy, major surgery, and date and type of eventually autologous
Table I Data recorded on four registration forms used by the Danish National Lymphoma Registry

\begin{tabular}{|c|c|}
\hline $\begin{array}{l}\text { Registration form and } \\
\text { time of registration }\end{array}$ & Variables \\
\hline Registration form & Diagnosis according to WHO (2008)/ICD-I0 \\
\hline \multirow[t]{15}{*}{ At diagnosis } & Date of diagnosis \\
\hline & Discordant lymphoma \\
\hline & Ann Arbor stage \\
\hline & B-symptoms \\
\hline & Largest tumor diameter \\
\hline & ECOG performance status \\
\hline & Planned treatment \\
\hline & Participation in clinical research protocol \\
\hline & Nodal and extranodal sites involved \\
\hline & Laboratory values (hemoglobin, \\
\hline & thrombocytes, leucocytes, lymphocytes, \\
\hline & albumin, calcium, bilirubin, alanine \\
\hline & transaminase, alkaline phosphatase, lactate \\
\hline & dehydrogenase, beta-2 microglobulin, and \\
\hline & immunoglobulins $\mathrm{A}, \mathrm{G}$, and $\mathrm{M}$ ) \\
\hline Primary treatment form & Chemotherapy \\
\hline \multirow{9}{*}{$\begin{array}{l}\text { At the end of first-line } \\
\text { treatment }\end{array}$} & Immunotherapy \\
\hline & Radioimmunotherapy \\
\hline & Radiotherapy \\
\hline & Major surgery \\
\hline & High-dose therapy with autologous stem-cell \\
\hline & transplantation \\
\hline & Other treatment \\
\hline & Response evaluation \\
\hline & Toxicity CTC grades III and IV \\
\hline Relapse & Date of relapse \\
\hline \multirow[t]{12}{*}{ At the time of relapse } & Histology (new biopsy) \\
\hline & CNS involvement at relapse \\
\hline & Treatment \\
\hline & Chemotherapy \\
\hline & Immunotherapy \\
\hline & Radioimmunotherapy \\
\hline & Radiotherapy \\
\hline & Major surgery \\
\hline & High-dose therapy with autologous stem-cell \\
\hline & transplant \\
\hline & Other treatment \\
\hline & Response evaluation \\
\hline \multirow[t]{4}{*}{ Follow-up/death } & Vital status \\
\hline & Date of follow-up/date of death \\
\hline & Remission status \\
\hline & Termination of outpatient follow-up \\
\hline
\end{tabular}

Abbreviations: WHO, World Health Organization; ICD-10, International Classification of Diseases, tenth edition; ECOG, Eastern Cooperative Oncology Group; CTC, common toxicity criteria; CNS, Central nervous system.

stem-cell therapy. Dates for starting and ending of the treatment are requested. A response assessment is required and has been adjusted to the different versions of the International Response Criteria for Malignant Lymphoma. ${ }^{2}$ Furthermore, toxicity assessment is recorded for patients experiencing toxicity grades III and IV. ${ }^{3}$ 


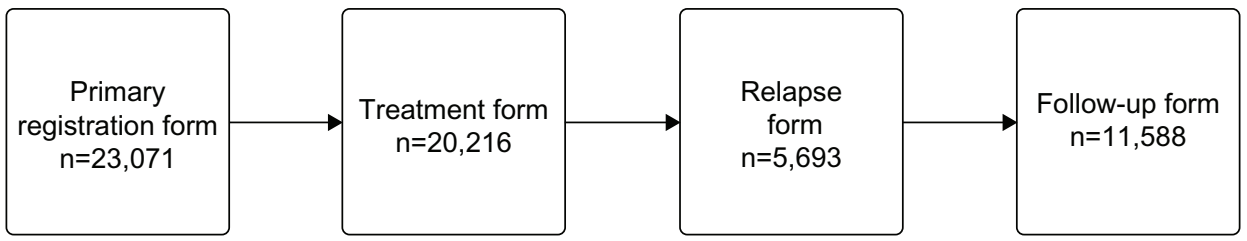

Figure I The four registration forms and the number registered in the LYFO for each form.

Notes: All patients have a primary registration form, whereas only patients receiving treatment have a treatment form, only patients who relapse have a relapse form, and only patients where outpatient follow-up is terminated have a follow-up form.

Abbreviation: LYFO, Danish National Lymphoma Registry.

\section{Relapse form}

In the case of clinical or histologically confirmed relapse or refractory disease, defined as progression within 3 months after termination of first-line treatment, a relapse form is requested. This form is also completed for all patients who were initially observed without need of treatment.

The relapse form requires date of relapse, lymphoma histology at relapse, treatment information of second-line treatment, and response assessment identical to the treatment form.

\section{Follow-up form}

A follow-up form is requested at death or termination of outpatient follow-up.

This form includes information on vital status, date of follow-up or death, and disease remission status.

The four schemes in the database are merged to an analyzable dataset, where new data fields are derived from the entered values in the schemes. This process utilizes calculation of a number of prognostic indexes such as the International Prognostic Index (IPI) ${ }^{4}$ and the Follicular Lymphoma International Prognostic Index ${ }^{5}$ and a number of nodal and extranodal sites, in addition to calculation of both result and process quality indicators. Result quality indicators are mortality 30 and 180 days after diagnosis for patients receiving treatment, response to first-line treatment and Kaplan-Meier survival estimates 1, 3, and 5 years after the time of diagnosis. The process quality indicators include time from diagnosis to start of treatment, fulfillment of entered data used in the International Prognostic Index, and the inclusion rate in clinical trials.

To ensure high registry completeness, the LYFO is crossreferenced with the Danish National Patient Registry and the National Pathology Registry. Since all patients with a hospital admission, both as inpatient and outpatient, are registered in the Danish National Patient Registry with diagnosis and date of contact, all patients referred to a hematological department are identified by this cross-reference. ${ }^{6}$ Departments can instantly retrieve lists of patients with missing registration in the database, both at time of diagnosis and time of an eventual relapse. All departments register in the LYFO and fulfill the demand of coverage of at least $90 \%$.

\section{Follow-up}

In addition to the follow-up form, which is completed at the time of termination of outpatient follow-up or death, whichever occurs first, a linkage to the Danish Civil Registration System secures that date of death is available. ${ }^{7}$ Thereby, no patient is lost to follow-up.

\section{Examples of research}

Data from the LYFO has for decades been used for both clinical epidemiological research and for monitoring the treatment of lymphoma patients in Denmark. ${ }^{8}$ The Danish Lymphoma Group, who runs the database, publishes annually a report based on data from the LYFO in collaboration with Registry Support Center of Epidemiology and Biostatistics (East). ${ }^{9}$ The quality indicators are presented for each department by year together with comments from clinicians and epidemiologists. The reports have shown improved 180 days mortality for patients with diffuse large B-cell lymphoma (DLBCL), improving from $12 \%$ to $10 \%$ during the past 4 years. The annual report is publically available and is used by both clinicians and for administrative purposes. In case of one department having significant worse outcome than the others, the administrative staff will examine the numbers and differences and draw the clinicians' attention to the differences in order to standardize treatment and outcome. As an example, the survival for patients with DLBCL was significantly lower in two out of ten departments in 2001-2007. The survival has increased, but is now at the same level for all departments due to publication of the survival results (Figure 2).

A substantial number of papers originated from the LYFO have been published in the past decade in international journals, and collaboration with other national databases has resulted in unique publications. ${ }^{9-13}$ In 2014 , a publication of mantle cell lymphoma showed male sex to be an independent negative prognostic factor, and that 


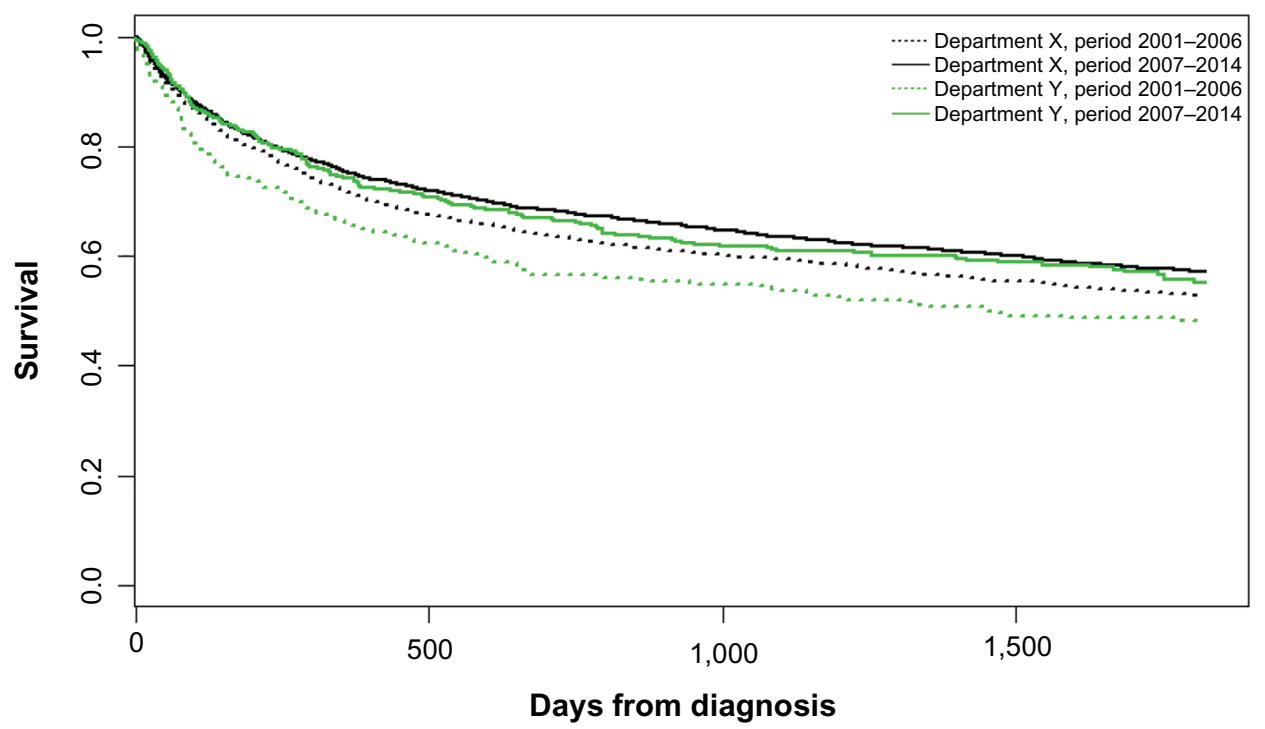

Figure 2 Survival for patients with diffuse large B-cell lymphoma, comparing departments with the poorest outcome (department $Y$ ) with better performing departments (department $X$ ) in the time periods 200I-2006 and 2007-2014, showing that survival is now equal between departments.

both Rituximab and autologous stem-cell transplant were independently associated with better outcome. ${ }^{11} \mathrm{~A}$ study on routine imaging in the follow-up setting after treatment for DLBCL compared the widespread use of routine imaging in Denmark with the more restrictive use in Sweden. No impact was found on survival, and the study concludes that routine imaging for DLBCL in the first complete remission is not recommended. ${ }^{13}$

Data quality in the LYFO has recently been measured through a validation process, and the data quality and coverage was found to be very high with positive predictive values for individual variables ranging from $87 \%$ to $100 \%$ using individual medical records as reference and a registration completeness of $94.9 \%$ using Danish National Patient Registry (DNPR) as reference. ${ }^{14,15}$

\section{Administrative issues and funding}

All Danish departments of hematology are responsible for reporting to the database. Health care professionals (eg, medical doctors, study nurses) report to the database, and consent is not required from patients due to the Danish legislation. Registration in the LYFO is approved by the National Board of Health and the Danish Data Protection Agency (2006-54-2093).

A data entry manual is publically available, and training is performed locally. Prior to submission of a form, an internal validation of the data fields is performed and the clinician has to clarify open issues (eg, date of diagnosis, lymphoma subtype) before submission of the form can be performed.
Furthermore, a warning sign appears if an abnormal value has been entered.

Funding from the Danish Regions allows the maintenance and development of the database and the database office. Registry Support Center of Epidemiology and Biostatistics East is responsible for IT support as well as statistical and epidemiological support.

\section{Conclusion}

The LYFO is a nationwide registry, established in 1982, with extensive information on all lymphoma patients treated at a department of hematology in Denmark. The database is used for quality assurance, clinical epidemiological research, and administrative purposes.

\section{Acknowledgments}

We wish to acknowledge all the patients diagnosed with lymphoma in Denmark, the local data managers at the participating centers, the Danish health registries, and databases for making this valuable registry possible. This article was funded by the Program for Clinical Research Infrastructure established by the Lundbeck Foundation and the Novo Nordisk Foundation and administered by the Danish Regions.

\section{Disclosure}

BA has received research funding from the Danish Cancer Society. All other authors report no conflicts of interest in this work. 


\section{References}

1. Swerdlow SH, Campo E, Harris NL, et al. WHO Classification of Tumours of Haematopoietic and Lymphoid Tissues. Lyon: IARC Press; 2008.

2. Cheson BD, Fisher RI, Barrington SF, et al; Alliance, Australasian Leukaemia and Lymphoma Group; Eastern Cooperative Oncology Group; European Mantle Cell Lymphoma Consortium; Italian Lymphoma Foundation; European Organisation for Research; Treatment of Cancer/Dutch Hemato-Oncology Group; Grupo Español de Médula Ósea; German High-Grade Lymphoma Study Group; German Hodgkin's Study Group; Japanese Lymphorra Study Group; Lymphoma Study Association; NCIC Clinical Trials Group; Nordic Lymphoma Study Group; Southwest Oncology Group; United Kingdom National Cancer Research Institute. Recommendations for initial evaluation, staging, and response assessment of Hodgkin and non-Hodgkin lymphoma: the Lugano classification. J Clin Oncol. 2014;32(27):1-10.

3. Common Terminology Criteria for Adverse Events (CTCAE) [webpage on the Internet]. Publish (4.0 C version). 2010;2009:0-71. Available from: $\mathrm{http} / / /$ ctep.cancer.gov/protocolDevelopment/electronic_applications/ docs/ctcaev3.pdf. Accessed February 11, 2016.

4. The International Non-Hodgkin's Lymphoma Prognostic Factors Project. A predictive model for aggressive non-Hodgkin's lymphoma. $N$ Engl J Med. 1993;329:987-994.

5. Solal-céligny P, Roy P, Colombat P, et al. Follicular lymphoma international prognostic index follicular lymphoma international prognostic index. Blood. 2011;104(5):1258-1265.

6. Schmidt M, Schmidt S, Sandegaard J, Eherenstein V, Pedersen L, Sørensen HT. The Danish National Patient Registry: a review of content, data quality, and research potential. Clin Epidemiol. 2015;7:449-490.

7. Schmidt M, Pedersen L, Sørensen HT. The Danish Civil Registration System as a tool in epidemiology. Eur J Epidemiol. 2014;7(1): 449-490.
8. Danish Lymphoma Group [webpage on the internet] Publications. Available from: http://www.lymphoma.dk/index.php?id=78,0,0,1,0,0. Accessed Marts 14, 2016.

9. Danish Lymphoma Group [webpage on the Internet]. LYFO Annually Report; 2013. Available from: http://lymphoma.dk/index. php?id=54,0,0,1,0,0. Accessed February 11, 2016.

10. Wästerlid T, Brown PN, Hagberg O, et al. Impact of chemotherapy regimen and rituximab in adult Burkitt lymphoma: a retrospective population-based study from the Nordic Lymphoma Group. Ann Oncol. 2013;24(7):1879-1886. doi: 10.1093/annonc/mdt058.

11. Abrahamsson A, Albertsson-Lindblad A, Brown PN, et al. Real world data on primary treatment for mantle cell lymphoma: a Nordic Lymphoma Group observational study. Blood. 2014;124(8):1288-1296. doi: 10.1182/blood-2014-03-559930.

12. El-Galaly T, Mylam KJ, Bøgsted M, et al. Role of routine imaging in detecting recurrent lymphoma: a review of 258 patients with relapsed aggressive non-Hodgkin and Hodgkin lymphoma. Am J Hematol. 2014;89(6):575-580. doi: 10.1002/ajh.23688.

13. El-Galaly TC, Jakobsen LH, Hutchings M, et al. Routine imaging for diffuse large B-cell lymphoma in first complete remission does not improve post-treatment survival: a Danish-Swedish population-based study. JClin Oncol. 2015;33(34):3993-3998. doi: 10.1200/JCO.2015.62.0229.

14. Arboe B, Galaly TCE, Clausen MR, et al. The Danish Lymphoma Registry has a high coverage and high data quality. EHA Learning Center. Poster presented at: Annual Meeting of the European Hematology Association; June 12, 2015; 100652; Vienna, Austria.

15. Sorensen HT, Sabroe S, Olsen J. A framework for evaluation of secondary data sources for epidemiological research. Int J Epidemiol. 1996;25(2):435-442.
Clinical Epidemiology

\section{Publish your work in this journal}

Clinical Epidemiology is an international, peer-reviewed, open access, online journal focusing on disease and drug epidemiology, identification of risk factors and screening procedures to develop optimal preventative initiatives and programs. Specific topics include: diagnosis prognosis, treatment, screening, prevention, risk factor modification,

Submit your manuscript here: http://www.dovepress.com/clinical-epidemiology-journa

\section{Dovepress}

systematic reviews, risk \& safety of medical interventions, epidemiology \& biostatistical methods, and evaluation of guidelines, translational medicine, health policies \& economic evaluations. The manuscript management system is completely online and includes a very quick and fair peer-review system, which is all easy to use. 